University of Montana

ScholarWorks at University of Montana

\title{
$5-2011$
}

\section{Modeling plant ranges over 75 years of climate change in California, USA: temporal transferability and species traits}

\author{
Solomon Z. Dobrowski \\ University of Montana - Missoula \\ James $\mathrm{H}$. Thorne \\ University of California - Davis \\ Johnathan A. Greenberg \\ University of California - Davis \\ Hugh D. Safford \\ USDA Forest Service Pacific Southwest Region \\ Alison R. Mynsberge \\ University of Montana - Missoula \\ See next page for additional authors \\ Follow this and additional works at: https://scholarworks.umt.edu/forest_pubs \\ Part of the Forest Management Commons \\ Let us know how access to this document benefits you.
}

\section{Recommended Citation}

Dobrowski, Solomon Z.; Thorne, James H.; Greenberg, Johnathan A.; Safford, Hugh D.; Mynsberge, Alison R.; Crimmins, Shawn M.; and Swanson, Alan K., "Modeling plant ranges over 75 years of climate change in California, USA: temporal transferability and species traits" (2011). Forest Management Faculty Publications. 9.

https://scholarworks.umt.edu/forest_pubs/9

This Article is brought to you for free and open access by the Forest Management at ScholarWorks at University of Montana. It has been accepted for inclusion in Forest Management Faculty Publications by an authorized administrator of ScholarWorks at University of Montana. For more information, please contact scholarworks@mso.umt.edu. 


\section{Authors}

Solomon Z. Dobrowski, James H. Thorne, Johnathan A. Greenberg, Hugh D. Safford, Alison R. Mynsberge, Shawn M. Crimmins, and Alan K. Swanson 


\title{
Modeling plant ranges over 75 years of climate change in California, USA: temporal transferability and species traits
}

\author{
Solomon Z. Dobrowski, ${ }^{1,5}$ James H. Thorne,${ }^{2}$ Jonathan A. Greenberg, ${ }^{3}$ Hugh D. Safford, ${ }^{4}$ \\ Alison R. Mynsberge, ${ }^{1}$ Shawn M. Crimmins, ${ }^{1}$ and Alan K. Swanson ${ }^{1}$ \\ ${ }^{1}$ Department of Forest Management, College of Forestry and Conservation, 32 Campus Drive, University of Montana, \\ Missoula, Montana 59812 USA \\ ${ }^{2}$ Information Center for the Environment, University of California, Davis, California 95616 USA \\ ${ }^{3}$ Center for Spatial Technologies and Remote Sensing, University of California, Davis, California 95616 USA \\ ${ }^{4}$ USD A Forest Service Pacific Southwest Region, 1323 Club Drive, Vallejo, California 94592 USA
}

Abstract. Species distribution model (SDM) projections under future climate scenarios are increasingly being used to inform resource management and conservation strategies. A critical assumption for projecting climate change responses is that SDMs are transferable through time, an assumption that is largely untested because investigators often lack temporally independent data for assessing transferability. Further, understanding how the ecology of species influences temporal transferability is critical yet almost wholly lacking. This raises two questions. (1) Are SDM projections transferable in time? (2) Does temporal transferability relate to species ecological traits? To address these questions we developed SDMs for 133 vascular plant species using data from the mountain ranges of California (USA) from two time periods: the 1930s and the present day. We forecast historical models over 75 years of measured climate change and assessed their projections against current distributions. Similarly, we hindcast contemporary models and compared their projections to historical data. We quantified transferability and related it to species ecological traits including physiognomy, endemism, dispersal capacity, fire adaptation, and commonness. We found that non-endemic species with greater dispersal capacity, intermediate levels of prevalence, and little fire adaptation had higher transferability than endemic species with limited dispersal capacity that rely on fire for reproduction. We demonstrate that variability in model performance was driven principally by differences among species as compared to model algorithms or time period of model calibration. Further, our results suggest that the traits correlated with prediction accuracy in a single time period may not be related to transferability between time periods. Our findings provide a priori guidance for the suitability of SDM as an approach for forecasting climate change responses for certain taxa.

Key words: California; climate change; endemism; fire adaptation; forecasting; hindcasting; historical data; species distribution models (SDM); species traits; transferability; Vegetation Type Map (VTM).

\section{INTRODUCTION}

Understanding climate change impacts on biota has long-term implications for social and economic welfare and conservation efforts (Parmesan 2006). Concern over climate change impacts has led to the widespread use of species distribution models (also known as climate envelope models or environmental niche models) for examining potential range shifts and extinction risks under climate change scenarios. These studies have projected increased extinction risks and range shifts for hundreds of plant and animal species (e.g., Peterson et al. 2002, Thomas et al. 2004, Iverson et al. 2007, Loarie et al. 2008). The potential impact of these studies on scientific, political, and public debate is high (Wiens et

Manuscript received 1 July 2010; revised 14 September 2010; accepted 4 October 2010. Corresponding Editor (ad hoc): M. C. Fitzpatrick.

${ }^{5}$ E-mail: solomon.dobrowski@cfc.umt.edu al. 2009), yet our understanding of their skill in predicting climate change responses is quite limited.

Species distribution models (SDMs) relate observations of species presence/absence to environmental predictors based on statistically or theoretically derived response functions (Guisan and Zimmerman 2000). The theory, implementation, and assumptions of SDMs have been widely reviewed (Guisan and Zimmerman 2000, Guisan and Thuiller 2005, Elith and Leathwick 2009). Their applications include the exploration of the ecological drivers of species distributions, predictive applications involving model-based interpolation in sampled regions, and prediction to new geographic or temporal domains (reviewed by Elith and Leathwick 2009). In this manuscript we focus on the latter application as it is pertinent to forecasting climate change impacts.

\section{Climate change and transferability}

Prediction into novel regions and times presents a unique challenge for SDMs because it can involve the 
extrapolation of models to spatial and temporal domains that differ from the domains in which models are calibrated (Williams and Jackson 2007, Fitzpatrick and Hargrove 2009). An assumption for projecting climate change responses is that SDMs are transferable through time. Transferability (also called "generality") addresses the ability of a model calibrated in one context to make useful predictions in a different context (Randin et al. 2006, Peterson et al. 2007, Phillips 2008). Studies have examined the spatial transferability of SDMs; i.e., they projected models into novel regions and compared their predictions to spatially independent species distribution data (Randin et al. 2006, Peterson et al. 2007, VanReusel et al. 2007, Duncan et al. 2009). Far fewer studies have examined the temporal transferability of SDMs (for exceptions, see Araújo et al. 2005, Pearman et al. 2008, Kharouba et al. 2009) despite its relevance to forecasting climate change responses.

There are many potential obstacles to SDM transferability. The most notable is the assumption of speciesenvironment equilibrium (Guisan and Zimmerman 2000, Nogués-Bravo 2009). This implies that species establishment will occur at any site that has changed from suboptimal to optimal environmental conditions (regardless of dispersal sources and limitations), and that mortality occurs at any site in which the opposite is true. Even over long time periods, species may not actually achieve equilibrium with climate due to dispersal limitations (Svenning and Skov 2004, Schurr et al. 2007). Similarly, species may persist at a site under nonoptimal climatic conditions (Sykes et al. 1996). SDMs also fail to account for changes in biotic interactions that can occur in novel temporal or spatial domains. For example, studies examining biotic invasions suggest that the spatial transferability of SDMs can be limited due to novel biotic interactions experienced in nonnative ranges (Fitzpatrick et al. 2007, Urban et al. 2007, Duncan et al. 2009, Medley 2010). Lastly, investigators commonly assume that climatic gradients are the dominant drivers of species distributions when using SDMs for climate change impact assessments, whereas the actual distributions of species used to calibrate these models reflect the combined influence of climate and other factors such as disturbance patterns and land use (Loehle and Leblanc 1996, Davis et al. 1998, Pearson and Dawson 2003). In practice, violation of any of these assumptions could affect the ability of SDMs to predict suitable habitat for species through time.

The temporal transferability of SDMs is also likely to vary among species and to be dependent upon ecological traits that reflect species-specific sensitivity to processes that constrain their distributions. Traits that help species achieve and maintain equilibrium with climate should result in greater SDM transferability. For instance, the ability of plants to migrate and keep pace with shifting climate may be critical for their survival, given the pace of anthropogenic warming and limited adaptation rates
(Jump and Penuelas 2005, Engler et al. 2009). In contrast, disturbance-adaptive traits may have the opposite effect on transferability because these traits can promote site fidelity (e.g., obligate seeding after fire; Syphard and Franklin 2010) and can decouple recruitment from climatic drivers. The relationship between SDM performance (within a single time period) and species traits has been widely studied (Kadmon et al. 2003, Thuiller et al. 2005, Guisan et al. 2007, Syphard and Franklin 2010). However, the traits that result in improved SDM performance within a single time period may not ensure transferability between time periods. Because there has been little work in this area, investigators have called for further studies examining the link between transferability and species traits (e.g., Randin et al. 2006), as these may provide a priori guidance of the suitability of SDM as an approach for forecasting climate change responses for certain taxa.

There are additional challenges unique to assessing the temporal transferability of SDM projections. SDM forecasts are largely untested because temporally independent validation data are rare (Araújo et al. 2005). Typically, reported model skill is determined by partitioning a single contemporary data set into calibration and test sets (herein referred to as "internal" evaluation, IE). In most cases, IE represents our only estimate of projection accuracy (the agreement between the predictions generated by the model and the known distribution of the species as expressed by temporally independent validation data). Further, there is a great deal of uncertainty in the validity of SDM projections, as studies have demonstrated that the chosen modeling technique (Guisan et al. 1999, Segurado and Araújo 2004), spatial scale (Luoto and Heikkinen 2008, Randin et al. 2009a, Seo et al. 2009), and evaluation methodology (Allouche et al. 2006) affect the outcome of future projections. To address this uncertainty, investigators have employed ensemble approaches that utilize different SDM algorithms on a common data set to characterize central tendencies in projections (e.g., Araújo and New 2007). However, even if consensus among projections from various SDM approaches is achieved, this represents precision, not accuracy.

A more robust approach for validating model projections through time is to calibrate SDMs with data from one time period and compare model projections to a separate time period (herein referred to as external evaluation, EE). For instance, models can be calibrated with historical $\left(t_{1}\right)$ data and forecasts can be compared to present-day $\left(t_{2}\right)$ data (Araújo et al. 2005). Similarly, models can be calibrated with contemporary data and hindcasts can be compared against historical data (Nogués-Bravo 2009). The use of historical data for validating SDM projections is vital because it provides the only means to directly assess the temporal transferability of SDMs and the factors that influence it.

Here we address two questions pertinent to the use of SDMs for forecasting climate change impacts: (1) Are 
SDM projections transferable in time? (2) Does temporal transferability relate to species ecological traits? We hypothesize the following:

1) Previous studies that examine temporal transferability of SDMs have demonstrated this for trees at the millennial time scale based on pollen distributions (Pearman et al. 2008), birds (Araújo et al. 2005), and butterflies (Kharouba et al. 2009). We extend this analysis to distributions of vascular plants during the last century.

2) Temporal transferability will vary by species traits.

2.1) Species that can achieve longer dispersal distances will exhibit greater transferability than species with limited dispersal, given that the former have a greater ability to colonize new sites and track changing climate.

2.2) Species with highly specialized fire adaptations will exhibit lower temporal transferability than species without fire adaptations. Fire is a critical disturbance agent in mediterranean ecosystems like California and many species there have life-history traits that shape their ability to establish in a site after fire. Consequently, fire-adapted species will be particularly sensitive to the inability of SDMs to account for dynamic disturbance patterns and will exhibit lower transferability (Guisan et al. 1999).

2.3) Endemic species will exhibit greater transferability than non-endemic species. Given that we are more likely to capture the entire realized niche of endemic species as compared to non-endemics, we expect to have greater transferability for endemics than non-endemics. For the latter, we may only capture a portion of the species-climate relationship, which may result in truncated response curves and lower transferability of these models through time (Fielding and Haworth 1995, Thuiller et al. 2004, McPherson and Jetz 2007).

2.4) Species with intermediate levels of prevalence should exhibit the highest transferability. Rare species will exhibit lower transferability due to poor detection, which can introduce error into model specification (Kadmon et al. 2003). Species that are common will also exhibit lower transferability, as it is more difficult to distinguish between suitable and unsuitable habitat for widespread habitat generalists (Segurado and Araújo 2004, Elith et al. 2006).

2.5) Deciduous species will exhibit lower transferability than evergreen species. Mediterranean-type climatic regions present a common set of selective forces that have resulted in convergence toward an evergreen, sclerophyllous habit in many plant lineages (Mooney and Dunn 1970). The ability of deciduous species to compete with evergreens in these regions is driven by interactions between local and regional gradients in soil moisture, drought seasonality, and disturbances such as fire (Kikuzawa 1991, Givnish 2002, Sugihara et al. 2006). Consequently, deciduous species are likely to have lower temporal transferability due to our inability to account for these local gradients and processes.
To assess these hypotheses, we developed SDMs for 133 vascular plant species using data from the mountain ranges of California, USA from two time periods: the 1930s and the present day. We forecast historical models forward 75 years and assessed projections against current distributions. Similarly, we hindcast contemporary models and compared their projections to historical data. In both cases, model skill was assessed using temporally independent data from new sites (external evaluation, EE). We relate transferability to species ecological traits including physiognomy, endemism, dispersal capacity, fire adaptation, and commonness.

California is ideal for addressing the hypothesis we have posed because its mediterranean climate, disturbance-prone ecosystems, and steep environmental gradients support a diverse array of habitats and species. The California floristic province (which covers $70 \%$ of California and only narrowly extends into southwestern Oregon and northern Baja, Mexico) is home to some 5500 native plant species, $40 \%$ of which are endemic to the region (Loarie et al. 2008, Thorne et al. 2009). As such, the province is considered a global biodiversity hotspot and is of conservation concern (Myers et al. 2000). California has experienced substantial and spatially variable climate change during the 20th century (Fig. 1). Average temperatures have increased by roughly $1.0^{\circ} \mathrm{C}$ during the last 50 years (LaDochy et al. 2007). Moreover, annual precipitation has increased in the northern region of the state (Hamlet et al. 2005), resulting in spatially variable trends in climatic water balance across the state (Fig. 1D). A detailed description of the effect of these climate changes on the distributions of the flora of California is beyond the scope of this analysis and is the focus of a separate analysis by the authors (in preparation). However, given the observed climate trends, we can assume that some regions of the state may be experiencing upslope or poleward shifts in species distributions due to warming, whereas other regions may be experiencing stasis or downslope shifts due to increased water availability. In summary, the diversity of species, habitats, and climate trends make California an ideal location to assess SDM transferability and the factors that influence it.

\section{Methods}

Study area

Our study area covers the dominant mountain ranges of California (Fig. 1A) and spans some $220000 \mathrm{~km}^{2}$. The study area encompasses all but two of the Jepson ecoregions (Hickman 1993) of the state (Central Valley and Sonora Desert; Fig. 1A), a major elevational gradient $(4000 \mathrm{~m})$, and large variations in latitude, longitude, moisture, and temperature.

\section{Climate data}

We produced summarized, gridded climate surfaces for two 30-year periods: 1905-1935 ("historic") and 1975-2005 ("current"). These surfaces were derived 
from the Parameter-elevation Regression on Independent Slopes Model (PRISM) (Daly et al. 2008) data set, a gridded climate data set covering the period of 1895 to present. PRISM data are widely used in North America and compare favorably to other gridded climate products for our study area (Daly et al. 2008). We downscaled the 800-m PRISM data to 400-m resolution using dynamic lapse rate estimates (Keane and Holsinger 2006). We derived a suite of bioclimatic variables, many of which are used (and described) in the BIOCLIM model (Busby 1991). Clear-sky radiation was modeled for the state at a 400-m resolution (ESRI 2008). Potential evapotranspiration (PET) was calculated via the Penman-Monteith method (Allen et al. 1998) using the downscaled PRISM data, radiation, and wind maps from the National Renewable Energy Laboratory (2009). Climatic water deficit was calculated by summing the difference between monthly normals of precipitation and PET. Seven climatic variables were selected that minimized collinearity $(\rho<0.85)$ between the predictors and that represent biologically meaningful combinations of the monthly climate variables. These include maximum temperature of the warmest period, minimum temperature of the coldest period, precipitation of the driest period, annual potential evapotranspiration (PET), PET seasonality, annual water deficit, and water deficit seasonality. Seasonality was calculated as the coefficient of variation of the monthly climate normals.

\section{Vegetation data sets}

We used species presence and absence data drawn from 13746 vegetation plots from the USDA Forest Service's Vegetation Type Map Project, VTM ( $t_{1}$ data). VTM was an effort to record California's vegetation between 1928 and 1940 (Wieslander 1935a, b, Thorne et al. 2008). This data set provides a unique view of the composition of vegetation of the mountains of California during the early 20th century. A single VTM plot comprised a vascular plant inventory of $800 \mathrm{~m}^{2}$ in forests and $400 \mathrm{~m}^{2}$ in other vegetation types, from which we extracted the presence and absence of target species. Georeferenced plot locations were estimated to be accurate within $200 \mathrm{~m}$ (Kelly et al. 2005). For modern data $\left(t_{2}\right.$ data), we compiled a collection of 28622 contemporary vegetation plots of species presence and absence surveyed by a variety of agencies and organizations, including inventories from the U.S. Forest Service, National Park Service, California Fish and Game, U.S. Geological Survey, California Native Plant Society, and data collected by university researchers including the authors. Plot locations for a subset of the study area (Sierra Nevada ecoregion) are shown in Fig. 2.

\section{Species selection and ecological traits}

We selected 133 vascular plant species for this analysis, the principal criterion for selection being that the species had adequate representation in both historical and contemporary data sets ( $\geq 30$ presences). The selected species included 5 herbaceous species, 99 shrub species, and 29 tree species. Median occurrences per species in the historical and modern data were 150 and 479 , respectively.

All species were characterized using five traits: physiognomy, endemism, dispersal, fire adaptation, and commonness. Within the tree and shrub life-forms, species were categorized by whether they had evergreen ( $n=81$ species) or deciduous $(n=47)$ physiognomy. Species were further classified as endemic $(n=34)$ or non-endemic $(n=99)$ to the California floristic province. Further, species were categorized by four dispersal strategies: A, anemochorous (wind dispersed; $n=33$ ); E, endozoochorous or epizoochorous (animal dispersed; $n=56) ; \mathrm{G}$, gravity dispersed $(n=28)$; and $\mathrm{S}$, autochorous (self disseminated; e.g., ballistic propagules; $n=16$ ). Species were also categorized into three classes representing their fire tolerance and adaptation level: low $(n=13)$, medium $(n=100)$, and high $(n=15)$. Species with low fire adaptation include shrubs and trees that have no stump or basal sprouting and do not exhibit facultative or obligate seeding after fire; trees in this category also have thin bark. Species with medium fire adaptation have medium to thick bark (if trees), facultative stump or basal sprouting, and low to medium degrees of serotiny. High fire adaptation is associated with obligate seeding shrub species and trees with a high level of serotiny. Lastly, commonness was quantified by taking the log-transformed average prevalence (proportion of occurrences) for each species from both the historical and contemporary data sets. Species ecological traits were determined using published accounts of species autecologies (Schopmeyer 1974, Burns and Honkala 1990, Hickman 1993, Franklin et al. 2004, Bonner and Karrfalt 2008, Syphard and Franklin 2010) and expert opinion. A list of species and species traits is provided in the Appendix.

\section{Study design}

The overall design of the study is summarized in Fig. 3. This is further divided into three parts: sample stratification, model fitting, and model evaluation.

Sample stratification.-Because the modern data were opportunistically sampled, we took several steps to assess and ameliorate potential sampling bias between the historical and modern periods. First, we conducted a principal components analysis (PCA) on the sampled climate data (climate values at locations of plots) for the historic, modern, and combined historic/modern inventories. In all three cases, the PCA reduced the dimensionality of the climate data to two axes that explained over $99 \%$ of the variance in climate space, the first of which (PC1) was loaded primarily on water availability (climatic deficit) and the second of which (PC2) was loaded principally on potential evapotranspiration (PET) (Table 1). We then produced $900(30 \times$ 

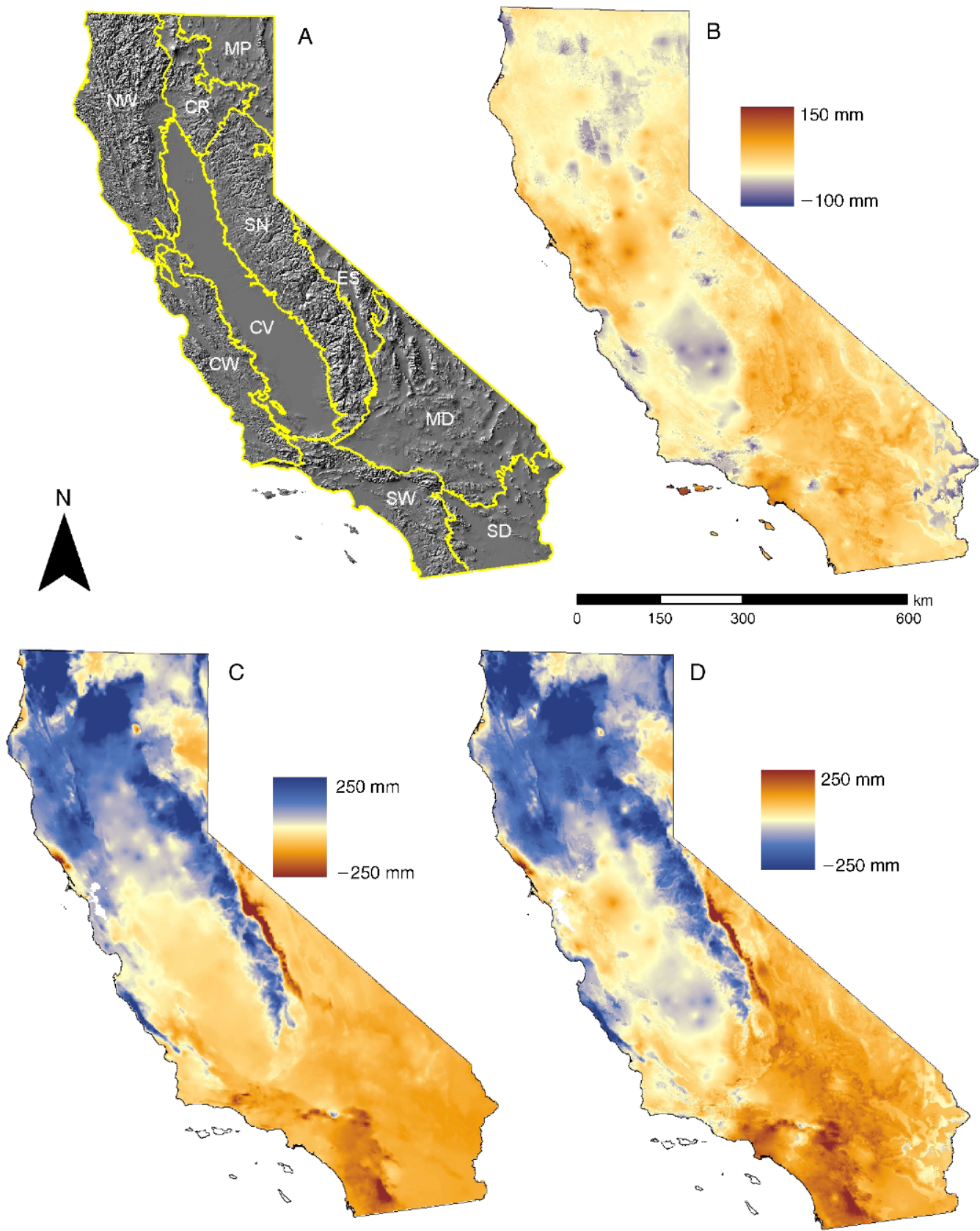

FIG. 1. (A) Study site/ecoregion boundaries in California, USA, per Hickman (1993) are outlined in yellow: CR, Cascade Ranges; CV, Central Valley; CW, Central Western; ES, East of Sierras; MD, Mojave Desert; MP, Modoc Plateau; NW, Northwestern; SD, Sonora Desert; SN, Sierra Nevada; SW, Southwestern. Positive and negative changes between the historical period (1905-1935) and modern period (1975-2005) are shown for (B) annual potential evapotranspiration, PET; (C) annual precipitation, $P$; and (D) climatic water deficit, PET $-P$.

30) bivariate bins of equal increments of PC1 and PC2 and tallied the number of plots that fell within each climate bin for both the historical and modern samples (Fig. 4). We then determined areas of climate space that were sampled in the modern data but not sampled in the historical data (non-analog sample, forecast), and similarly, climate space sampled in the historical data but not in the modern data (non-analog sample, hindcast) (Fig. 4). To provide a conservative comparison, we chose a threshold of five plots for treating each climate bin as being "sampled." We then identified plots within overlapping and nonoverlapping climate spaces to stratify our historical and modern data set into three classes for assessing metrics of EE and transferability: 


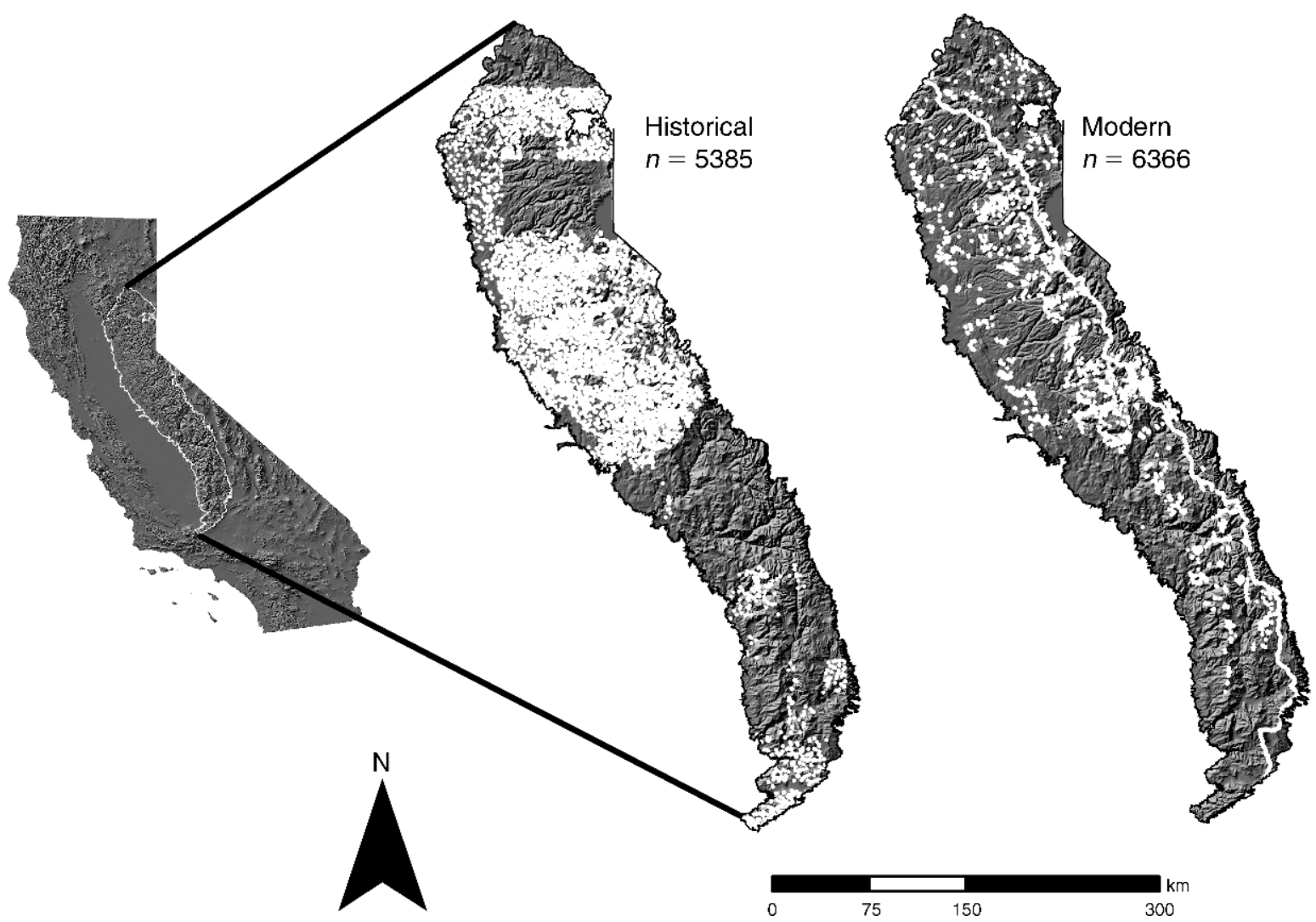

FIG. 2. Location of historical and modern plots for plant distributions in the Sierra Nevada ecoregion of California, USA.

(1) full sample, with no sample stratification; (2) analog sample, in which the climate space of the samples overlaps between the historical and modern periods; and (3) non-analog sample, in which the climate space of the samples does not overlap for either the forecast or hindcast.

Model fitting.-We used multiple modeling techniques for each species using the BIOMOD suite of tools (Thuiller et al. 2009). Our choice of modeling techniques was aimed at capturing the variability in classes of algorithms (e.g., parametric and nonparametric approaches; regression-based and machine-learning approaches) and demonstrated performance in previous studies. SDMs employed include generalized linear models, GLM (McCullagh and Nelder 1989), and generalized additive models, GAM (Hastie and Tibshirani 1990), as examples of parametric and semi-parametric regression-based approaches, as well as random forest, RF (Breiman 2001), and generalized boosting models, GBM (De'ath 2008, Elith et al. 2008), as examples of techniques developed in the machinelearning community.

For GAM and GLM, model selection was conducted using a forward and backward stepwise procedure based on the Akaike Information Criterion (AIC). For GLM, each term could be dropped, fit as a linear term, or fit as

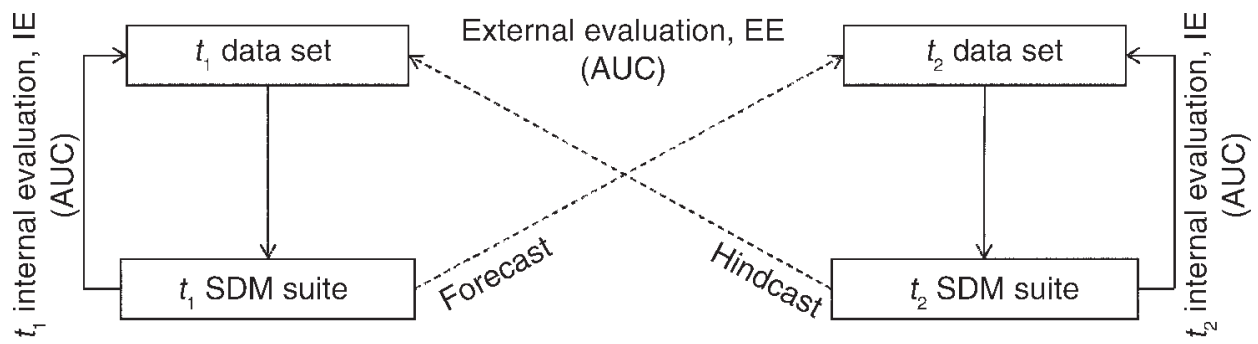

FIG. 3. Experimental design. Four species distribution model (SDM) approaches for each species were evaluated with data from the same time period used to calibrate models (internal evaluation), and forecasts or hindcasts were evaluated using data from a different time period (external evaluation); $t_{1}$ represents the historical period (1930s); $t_{2}$ represents the modern period (2000s). Both internal and external evaluation were conducted using the area under the curve statistic (AUC). 
a second- or third-order polynomial. For GAM, each term was evaluated using a cubic spline smoother with three degrees of freedom, as a linear term, or dropped from the model. We built GBM models using 2000 trees with a shrinkage parameter of 0.01 , a 0.5 -bag fraction, and an interaction depth of 3 . We derived an out-of-bag estimate of the optimal number of boosting iterations required to model probability of presence. We then used the optimal number of iterations from the boosting sequence to predict probability of presence. For RF models, independent bootstrap samples from the data were used to grow 750 trees for each species. Probability of presence was determined using the proportion of presence votes from each of the 750 trees fit in a given RF for a species.

Model evaluation.-Internal evaluation (IE) for models at times $t_{1}$ and $t_{2}$ was conducted using a random data-partitioning of $70 \%$ training data and 30\% test data. This data-splitting was repeated three times for each model, and model skill was averaged across repetitions to estimate IE. The area-under-the-curve (AUC) statistic (Fielding and Bell 1997) was calculated to determine model skill. We chose the AUC statistic because it does not require the selection of a probability threshold to convert probability of presence to a categorical output of present or absent. External evaluation (EE) was conducted by comparing forecasts and hindcasts to independent data from each relevant time period (Fig. 3) using each sample stratification (full, analog sample, non-analog sample). The AUC statistic was also used for EE. We averaged AUC values across model types for each species and used these average metrics of IE and EE to assess differences between groups (IE vs. EE; $t_{1}$ vs. $t_{2}$; forecast vs. hindcast; sample stratification) using Wilcoxon signed-rank tests for paired comparisons and the Tukey hsd test $(\alpha=0.05)$ for multiple-comparison tests.

In addition to the AUC metric, we also determined the proportion of false positive errors and false negative errors based on IE and EE from our historical model forecasts. We translated continuous probability estimates to a categorical output of presence/absence using a threshold that minimized the difference between the specificity and sensitivity of our models (Cantor et al. 1999). Using a paired $t$ test for both IE and EE, we assessed whether the mean false positive fraction across species differed significantly from the false negative fraction.

\section{Transferability}

The temporal transferability between the two time periods was assessed using two criteria. The first was simply the EE values (AUC), the capacity of the model to distinguish between suitable and unsuitable habitat in a different time period. The second was that the IE of a model fitted in $t_{1}$ should be comparable to the EE of the same model projected into $t_{2}$, and vice versa. To assess the second criterion, we adapted a transferability index
TABLE 1. Summary of principal component analysis (PCA) statistics and PC loadings of climate variables sampled from the combined historic/modern inventory data.

\begin{tabular}{lrr}
\hline \hline \multicolumn{1}{c}{ PCA statistics and components } & PC 1 & PC 2 \\
\hline Standard deviation & 767.60 & 161.34 \\
Proportion of total variance explained & 0.95 & 0.04 \\
Cumulative proportion & 0.95 & 0.99 \\
PC loadings & & \\
$\quad$ Max. temperature, warm period & & \\
Min. temperature, cold period & & \\
Precipitation, dry period & 0.32 & 0.94 \\
Annual potential evapotranspiration & & \\
Potential evapotranspiration seasonality & & \\
Annual climatic water deficit & 0.94 & -0.31 \\
Climatic water deficit seasonality & & 0.11 \\
\hline
\end{tabular}

Notes: Blank cells indicate that the component did not have loadings on the axis. Climatic water deficit was calculated by summing the difference between monthly normals of potential evapotranspiration and precipitation. Seasonality was calculated as the coefficient of variation of the monthly climate normals.

(TI) developed by Randin et al. (2006):

$$
\begin{aligned}
\mathrm{TI}= & {\left[0 . 5 \left(\left[1-\frac{\left|\mathrm{AUC}_{t 1 \rightarrow t 1}-\mathrm{AUC}_{t 1 \rightarrow t 2}\right|}{0.5}\right]\right.\right.} \\
& \left.\left.+\left[1-\frac{\left|\mathrm{AUC}_{t 2 \rightarrow t 2}-\mathrm{AUC}_{t 2 \rightarrow t 1}\right|}{0.5}\right]\right)\right] \\
& \div\left(1+|| \frac{\mathrm{AUC}_{t 1 \rightarrow t 1}-\mathrm{AUC}_{t 1 \rightarrow t 2} \mid}{0.5} \mid\right. \\
& \left.-\left|\frac{\mathrm{AUC}_{t 2 \rightarrow t 2}-\mathrm{AUC}_{t 2 \rightarrow t 1} \mid}{0.5}\right|\right)
\end{aligned}
$$

where $\mathrm{AUC}_{t 1 \rightarrow t 1}$ is the evaluation of the model fitted in the historical time period and evaluated on the same time period using data partitioning (IE) and $\mathrm{AUC}_{t 1 \rightarrow t 2}$ fits the model with historical data and evaluates it on modern data (EE). The transferability index (TI) was calculated for each species and quantifies the decrease in the AUC statistic when going from IE $\left(\mathrm{AUC}_{t 1 \rightarrow t 1}\right.$ and $\left.\mathrm{AUC}_{t 2 \rightarrow t 2}\right)$ to $\mathrm{EE}\left(\mathrm{AUC}_{t 1 \rightarrow t 2}\right.$ and $\left.\mathrm{AUC}_{t 2 \rightarrow t 1}\right)$. Values of the index can range from 0 to 1 , with high values representing strong agreement between IE and EE for both the forecast and hindcast, whereas low values represent little agreement between these metrics. We calculated TI for the three sample stratifications using AUC values averaged across models.

Transferability and species traits.-We used several methods to determine whether AUC and TI values were related to species ecological traits. Given an unbalanced design, we used the Wilcoxon signed-rank test for pairwise comparisons between groups. Additionally, for the TI metric, we used simple regression models to relate TI values to individual species traits. We also regressed TI values against all significant predictors from the previous single-term tests. Due to the potential for nonindependence between species due to phylogenetic relatedness, we developed a linear mixed-effects model with species traits as fixed effects and family and 


\section{Number of plots}
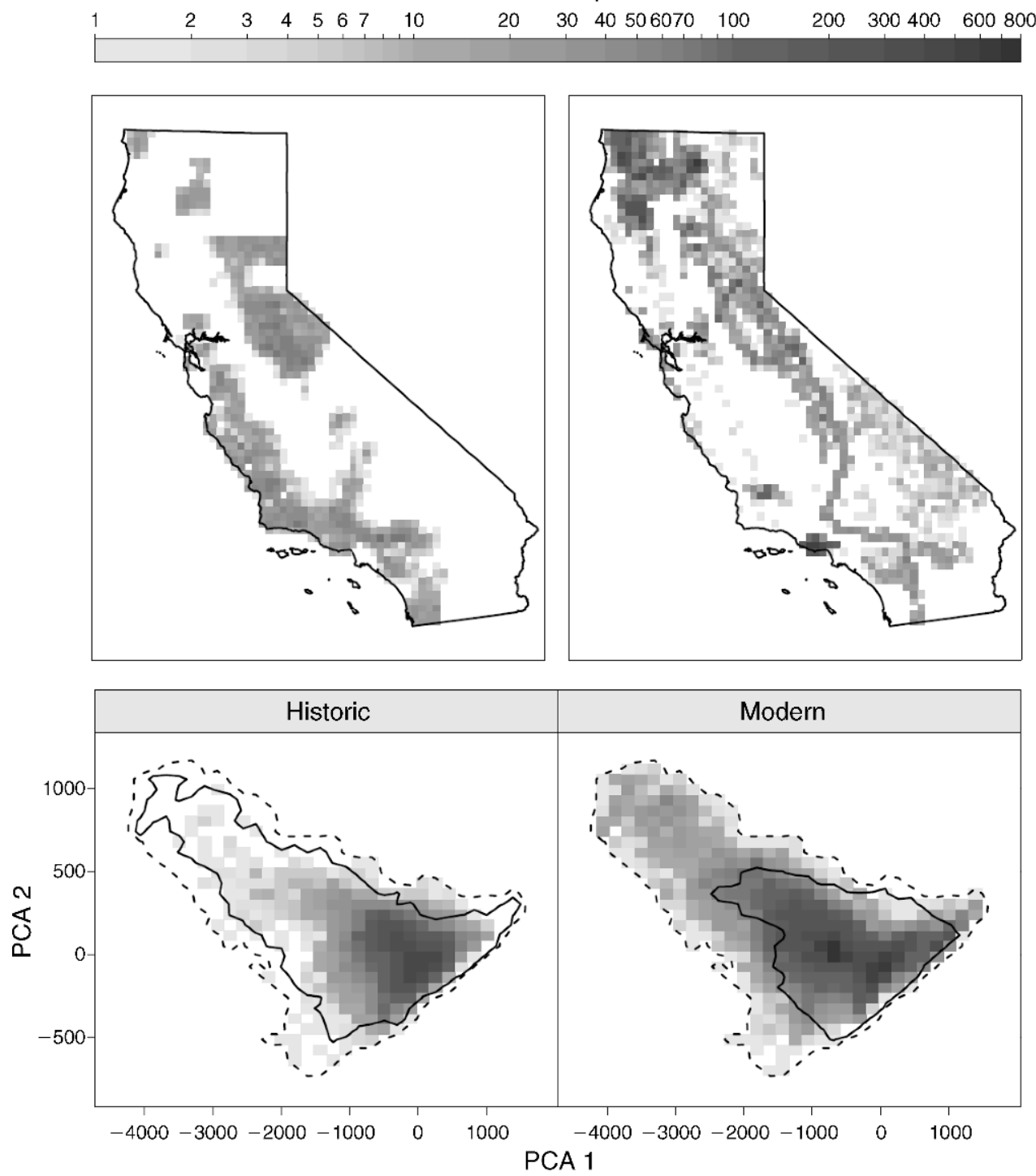

FIG. 4. Geographic distribution and sampling intensity of historical and modern plots within the study region (upper panels). The gray scale key represents the number of plots within $15 \times 15 \mathrm{~km}$ cells (upper panels) and the number of plots in bivariate climate space bins (lower panels). The two principal components were derived from seven climate variables used to fit SDMs; they loaded most heavily on climatic water deficit (PCA 1) and potential evapotranspiration (PCA 2). In the lower panels, the outer dashed line represents the climate space sampled in at least one time period. The inner solid line represents climate space sampled by a minimum of five plots per bin in the other time period. The climate space between the solid contour and the dashed contour represents the climate space that was not adequately sampled in the other time period (i.e., non-analog sample). For example, the climate space between the dashed and solid contour lines in the lower right-hand plot represents the non-analog sample for the forecast direction.

genus as random nested factors. Parameter estimation was conducted using restricted maximum likelihood. All statistical analyses were conducted using $\mathrm{R}$ version 2.9 (R Development Core Team 2009).

\section{RESULTS}

\section{Internal and external evaluation}

Mean AUC metrics of IE for all 133 species and four models assessed at $t_{1}$ and $t_{2}$ were 0.89 and 0.91 , respectively (Table 2), suggesting that SDMs were well calibrated. These values differed between time periods (Wilcoxon signed-rank test, $P=0.006$ ). For EE, mean AUC values averaged for all species and models varied between 0.81 and 0.78 , depending on sample stratification and direction of projection (forecast or hindcast). IE AUC values were greater than EE by an average of 0.10 across all model types and time periods. All paired comparisons of model-averaged IE vs. EE values were significantly different (all paired Wilcoxon signed-rank 
TABle 2. Mean AUC values for 133 vascular plant species by four modeling approaches, internal and external evaluation (forecasts and hindcasts), and sample stratification.

\begin{tabular}{|c|c|c|c|c|c|c|c|c|}
\hline \multirow{4}{*}{$\begin{array}{l}\text { Model } \\
\text { approach }\end{array}$} & & & \multicolumn{6}{|c|}{ External evaluation, EE } \\
\hline & & & \multicolumn{3}{|c|}{ Forecast, by sample type } & \multicolumn{3}{|c|}{ Hindcast, by sample type } \\
\hline & \multicolumn{2}{|c|}{ Internal evaluation, IE } & \multirow{2}{*}{$\begin{array}{c}\text { Full } \\
\text { sample }\end{array}$} & \multirow{2}{*}{$\begin{array}{l}\text { Analog } \\
\text { sample }\end{array}$} & \multirow{2}{*}{$\begin{array}{c}\text { Non-analog } \\
\text { sample }\end{array}$} & \multirow{2}{*}{$\begin{array}{c}\text { Full } \\
\text { sample }\end{array}$} & \multirow{2}{*}{$\begin{array}{l}\text { Analog } \\
\text { sample }\end{array}$} & \multirow{2}{*}{$\begin{array}{c}\text { Non-analog } \\
\text { sample }\end{array}$} \\
\hline & $t_{1}$ & $t_{2}$ & & & & & & \\
\hline GAM & 0.90 & 0.90 & 0.82 & 0.83 & 0.80 & 0.83 & 0.83 & 0.81 \\
\hline GBM & 0.88 & 0.91 & 0.80 & 0.80 & 0.79 & 0.81 & 0.81 & 0.78 \\
\hline GLM & 0.89 & 0.90 & 0.80 & 0.82 & 0.77 & 0.82 & 0.82 & 0.79 \\
\hline $\mathrm{RF}$ & 0.89 & 0.92 & 0.78 & 0.79 & 0.78 & 0.79 & 0.79 & 0.79 \\
\hline Mean & $0.89^{\mathrm{a}}$ & $0.91^{\mathrm{b}}$ & $0.81^{\mathrm{c}}$ & $0.80^{\mathrm{c}}$ & $0.78^{\mathrm{c}}$ & $0.81^{\mathrm{c}}$ & $0.81^{\mathrm{c}}$ & $0.80^{\mathrm{c}}$ \\
\hline
\end{tabular}

Notes: Key to abbreviations: AUC, area under the curve statistic; GAM, generalized additive modeling; GBM, generalized boosting models; GLM, generalized linear modeling; and RF, random forest. Historical $\left(t_{1}\right)$ and present-day $\left(t_{2}\right)$ data are used for IE. For "full sample" there is no sample stratification; for the analog sample, the climate space of the samples overlap between the historical and modern periods; for the non-analog sample, the climate space of the samples does not overlap for either the forecast or hindcast. See Methods for further detail.

All pairwise comparisons of IE vs. EE are significantly different based on paired Wilcoxon-signed rank tests $(P<0.001)$. Columns with different superscript letters have model-averaged AUC values that are statistically different based on Wilcoxon signed-rank tests $(P<0.001)$ for paired comparisons and the Tukey hsd test $(\alpha=0.05)$ for comparisons involving three or more groups.

tests have $P<0.01)$. There was consistently greater variance in AUC values from EE than in AUC values from IE (Fig. 5). Approximately $20 \%$ of the species had EE values (from the full and analog samples) that were less than 0.7 (a commonly used threshold to discern between poor and fair models), whereas $1.5 \%$ of the species had IE values less than 0.7 .

The dominant error types for historical models differed between IE and EE. The mean false positive fraction and false negative fraction for IE were 0.148 and 0.149 , respectively, and did not differ based on a paired $t$ test $(P=0.46)$. For $\mathrm{EE}$, the mean false negative fraction (0.34) was greater than the mean false positive fraction $(0.21)$ based on the same test $(P=0.0002)$.

Sample stratification had a minimal effect on measures of EE (Fig. 5). EE metrics for the non-analog sample were lower, on average, than the full and analog sample, although the difference was not statistically significant (based on a Tukey hsd test, $\alpha=0.05$ ). Variance in EE was equal between the full and analog samples, but significantly greater for the non-analog sample for the forecast direction (Levenes test; $P<$ 0.0001). The choice of model algorithm resulted in small, but significant, differences in EE values (Tukey hsd test, $\alpha=0.05)$. The performance of the model algorithms (EE) could be ranked as follows: GAM $>$ GBM $=$ GLM $>$ RF. However, differences observable among model algorithms were small compared to the variance in AUC values among species (Fig. 5).

\section{Transferability}

TI values ranged from 0.30 to 0.98 depending on the sample stratification (Fig. 6). TI values for the nonanalog sample were lower than values from the full and analog samples, which showed no discernible difference (Tukey hsd test, $\alpha=0.05$; Fig. 6). Consequently, we only present results from the "full" non-stratified data set.
Pairwise tests suggest that AUC and TI values vary by species ecological traits (Fig. 7). We omitted the herbaceous species from analyses because of inadequate replication ( $n=5$ species) and because other ecological categorizations used in the analysis were not relevant to herbaceous species (e.g., deciduous vs. evergreen). For the remaining 128 species, deciduous species showed lower AUC and TI values than evergreen species, although the differences were not statistically significant. Endemic species had lower AUC values in the hindcast direction (Wilcoxon signed-rank test, $P=0.005$ ) and lower TI values (Wilcoxon signed-rank test; $P=0.021$ ) than non-endemic species. AUC values for the hindcast direction and mean TI values also varied among dispersal types. AUC values and TI values by dispersal type were distributed from highest to lowest as follows: wind (A), animal (E), gravity (G), and ballistic dispersal (S) (Fig. 7). Species that showed little adaptation to fire (low) had higher AUC and TI values than those with medium and high levels of fire adaptation (Fig. 7). Lastly, AUC and TI values had a discernible quadratic relationship ( $F$ test; $P<0.06$ ) to commonness (test of a linear relationship was not significant based on $F$ test; $P$ $>0.1)$.

Results from regression models relating $\mathrm{TI}$ to ecological traits are summarized in Table 3. Endemism, dispersal, and fire adaptation were significant in singleterm models. Commonness had a marginal effect $(P=$ $0.06)$. These fixed terms remained significant in a linear mixed-effects regression model (Table 3). Residuals from this model were normally distributed (ShapiroWilks normality test; $P=0.30$ ).

\section{DISCUSSION}

\section{Are SDM projections transferable in time?}

Internal evaluation metrics of SDM performance are consistently higher than model projection accuracy for both forecasting and hindcasting when assessed using 

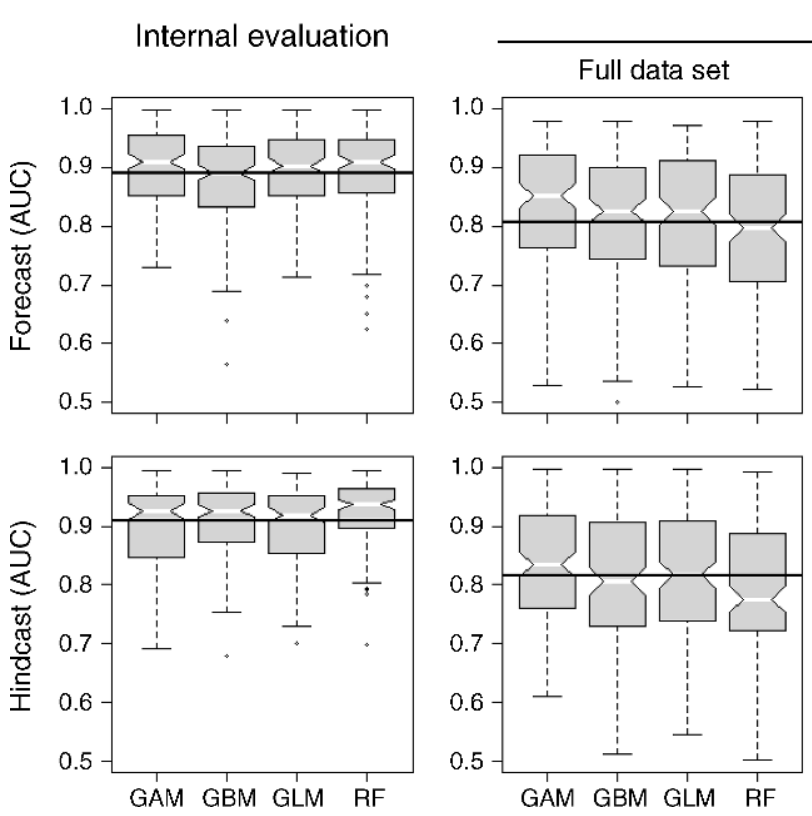

External evaluation
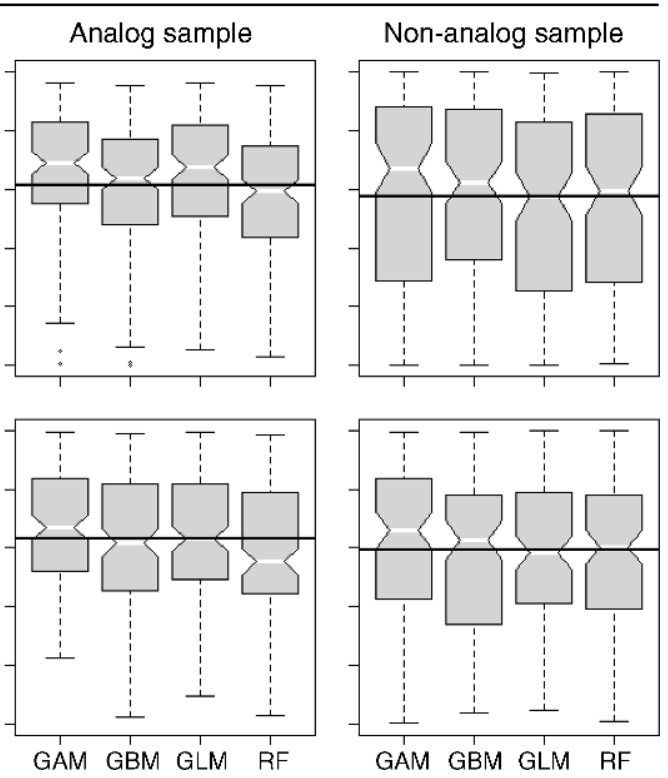

FIG. 5. Box plots for AUC (area under the curve statistic) values for internal evaluation (IE) and external evaluation (EE) by sample stratification (see Methods) for forecast ( $t_{1}$ model) and hindcast ( $t_{2}$ model) projections. AUC values for four modeling approaches (GAM, generalized additive models; GBM, generalized boosting models; GLM, generalized linear models; RF, random forest) for 133 species are presented. Boxes delimit the interquartile range, with girdles at the median and notches to indicate the median's 95\% confidence intervals. Horizontal lines denote mean AUC values across model types.

temporally independent validation data. During a 75year period, this bias is on the order of $15 \%$ overestimation. We expect that differences between IE and EE would be even greater for SDMs based on future climate scenarios, given that we used measured and interpolated climate values over the study period as opposed to climate simulations that are likely to contain even higher uncertainty (Palmer 2000, Murphy et al. 2004). These findings are not entirely surprising, as validation based on temporally and spatially independent data is likely to result in more realistic (and lower) estimates of model skill (Araújo et al. 2005, Randin et al. 2006). Our findings for plants are consistent with previous studies for birds (Araújo et al. 2005) and butterflies (Kharouba et al. 2009). This suggests that for a broad range of taxa, IE may overestimate the skill of SDMs for generating projections under future climate scenarios.

The average transferability of SDMs in this study was fair to good. We found that mean AUC values based on EE were consistent with those reported elsewhere (Araújo et al. 2005). Despite this, 20\% of the species that we modeled had weak transferability based on our first criterion (AUC $<0.7$ ). This is indicative of the high level of variability in measures of EE, variability that was substantively underestimated by IE. Greater variability in measures of EE as compared to IE was also observed by Boyce et al. (2002) and Araújo et al. (2005) when examining temporal transferability, and by Randin et al. (2006) when examining spatial transferability of SDMs. These results suggest that SDMs can become erratic when transferring projections in space and time (Kharouba et al. 2009).

Our understanding of the nature of prediction errors made by SDMs is also affected by whether our inferences are based on IE or EE. Based on the IE of our historical models, we would assume that model errors were random, with similar false negative and false positive error rates. In contrast, validated projections from these historical models suggest that model errors were not random, with higher false negative error rates

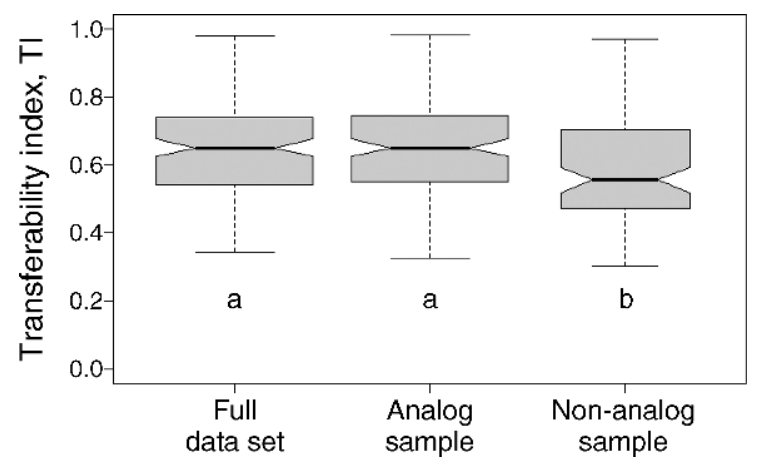

FIG. 6. Box plot of transferability index (TI) values by sample stratification (see Methods) for each of 133 species. Boxes delimit the interquartile range, with girdles at the median and notches to indicate the median's $95 \%$ confidence intervals. Different lowercase letters indicate significantly different groups as determined using the Tukey hsd test $(\alpha=0.05)$. 

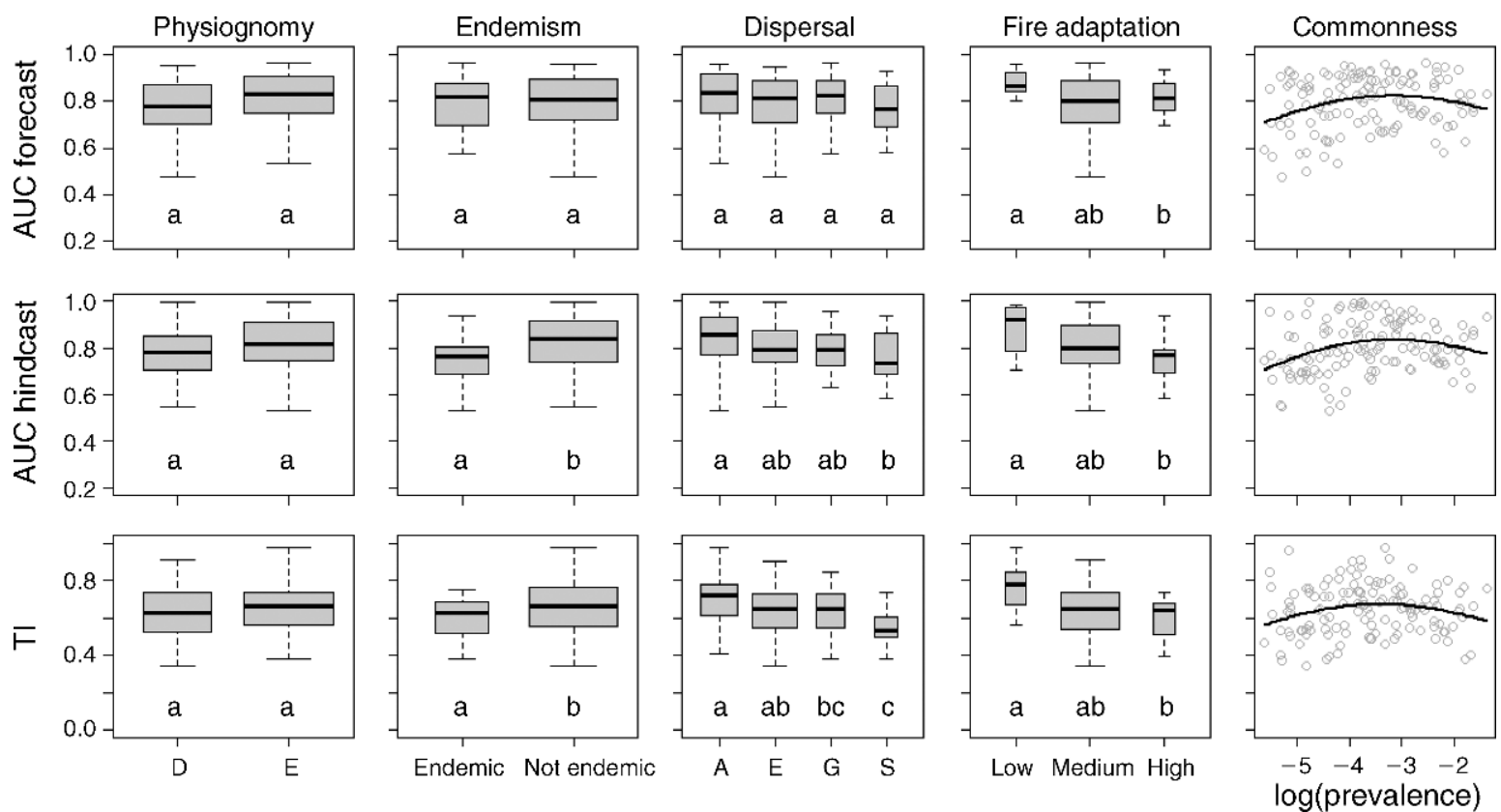

FIG. 7. Plots illustrating the influence of species ecological traits on temporal transferability, characterized using EE AUC values and the transferability index (TI). The width of each boxplot is proportional to the sample size of that group. Different lowercase letters denote significantly different groups as determined using pairwise comparisons of groups based on a Wilcoxon signed-rank test $(P<0.01)$. Categories for physiognomy are deciduous $(\mathrm{D})$ and evergreen $(\mathrm{E})$; for dispersal, wind dispersed (A), animal dispersed (E), gravity dispersed $(\mathrm{G})$, ballistically dispersed (S); for fire adaptation, plants with thin bark and no postfire sprouting have low adaptation, plants with facultative sprouting and medium to thick bark for trees have medium adaptation, and plants with obligate postfire seeding and high level of serotiny have high adaptation. Relationships between commonness (logtransformed prevalence) and AUC and between commonness and TI are shown using a quadratic relationship $(F$ test, $P<0.05)$. Further details are provided in Methods.

than false positive rates. This may be due to the persistence of long-lived woody species in regions that are no longer "climatically suitable." It could also be due to underestimating the breadth of the fundamental niche of the species examined. Further analysis is needed to decouple these causes. Notwithstanding, we urge caution when examining error types made by SDMs, because the relative proportion of error types is highly sensitive to the probability threshold chosen for converting probability of presence to categorical outputs (Liu et al. 2005).

Sampling bias.-Sampling bias was apparent between the two periods used in this study. As the modern data were collected in an opportunistic fashion and we cannot augment historical data, we developed an approach to identify sampling bias and its influence on transferability. We anticipated that sampling bias would be lowest in the analog sample, increasing with the full sample, and greatest in the non-analog sample. Consequently, we expected models to perform more poorly in the non-analog and full samples as compared to the analog sample, because the former involved making projections into climatic space that was not encountered in the model calibration. We found that there were no discernible differences in AUC values between the full and analog samples. Further, we found that, although there was evidence that the non-analog sample had lower mean EE values than the full and analog samples, these differences were not statistically significant. Instead, for the forecast direction, the variance in AUC values for the non-analog sample was significantly greater than that of the full and analog samples. This was not the case for the hindcast direction, suggesting that there were forms of asymmetry in transferability between time periods in our study. This asymmetry was expected because the historical model was calibrated with data that encompassed a narrower range of sampled climatic space than the modern data (Fig. 4). Thus, forecasts from historical models encountered a greater challenge to transferability than modern models

TABLE 3. Proportion of variance explained for single-term linear models relating transferability index (TI) values to species ecological traits and effects test for a linear mixedeffects (LME) regression model.

\begin{tabular}{lccccc}
\hline \hline \multirow{2}{*}{ Term } & \multicolumn{2}{c}{$\begin{array}{c}\text { Single-term } \\
\text { regression }\end{array}$} & & \multicolumn{2}{c}{$\begin{array}{c}\text { Fixed effects } \\
\text { from LME }\end{array}$} \\
\cline { 2 - 3 } \cline { 6 - 7 } & $R^{2}$ & $P$ & & $F$ & $P$ \\
\hline Physiognomy & 0.01 & 0.22 & & \\
Endemism & 0.03 & 0.038 & & 6.53 & 0.013 \\
Dispersal & 0.10 & 0.005 & & 6.48 & 0.0008 \\
Fire adaptation & 0.10 & 0.001 & & 3.39 & 0.041 \\
Poly(commonness, 2) & 0.04 & 0.06 & & 3.22 & 0.047 \\
\hline
\end{tabular}


encountered when hindcasting: historical models had to make projections not only into a novel time period, but also had to extrapolate into unsampled climatic regions. This resulted in greater variance in model performance and lower TI values (Fig. 6).

The use of temporally independent data raises the likelihood of encountering what Phillips (2008) describes as "geographic sampling bias" between time periods. This kind of bias will be a greater problem for presenceonly modeling approaches as compared to presence/ absence approaches because, in the former, bias will affect presence data but not background (pseudoabsence) data (Phillips et al. 2009). Further, this type of bias will probably affect studies conducted at local to regional scales more than studies conducted at broad scales. Studies with smaller extents and finer grains are more likely to capture a subset of the speciesenvironment relationship as compared to broadscale studies (Fielding and Haworth 1995, Thuiller et al. 2004), forcing models to extrapolate to conditions they were not calibrated on. However, from a management and conservation perspective, climate change impacts are intrinsically local (Wiens and Bachelet 2010) and there is an increasing awareness of the limitations of coarse-scaled analysis for forecasting climate change responses (Luoto and Heikkinen 2008, Randin et al. 2009a, Seo et al. 2009, Wiens and Bachelet 2010).

Reduced transferability may also be due to making projections into novel "non-analog" climates. This could have occurred if novel climates (sensu Williams et al. 2007) were encountered in the modern period that were not encountered in the historical period. We examined the entire climate space of California in both the historical and modern periods (using the same bivariate approach described for identifying sample bias; results not shown) and found that few regions in the state experienced novel climates. Our climate data suggest that temperature has increased in California between the historical and modern periods by $0.45^{\circ} \mathrm{C}$ and $0.80^{\circ} \mathrm{C}$ for annual mean and minimum temperature, respectively. These values are consistent with observations of earlier snowmelt in the western United States (Dettinger and Cayan 1995, Cayan et al. 2001) and with evidence of an extended summer drought period in western states (Westerling et al. 2006). However, this level of warming is small in comparison to the total amount of climatic variation present in the study region. Novel climates appear to be localized to the hottest environments in the state (deserts), and few of the species examined here were likely to have encountered climate that was novel over the 75-year study period: climatic conditions that were not experienced somewhere else in the species range.

\section{Does temporal transferability relate to species ecological traits?}

Many studies have demonstrated that our ability to model species-environment relationships in a single time period varies by species traits (Kadmon et al. 2003, Guisan et al. 2007, McPherson and Jetz 2007, Syphard and Franklin 2010). To our knowledge, the work of Kharouba et al. (2009) was the first study that examined the influence of species traits on temporal transferability. These authors related temporally independent estimates of SDM projection accuracy for butterflies to niche breadth and wing size (a measure of dispersal ability) and found that transferability declined for widely distributed species and showed inconclusive results for wing size. We expand this type of analysis to vascular plants.

The temporal transferability of SDM projections varied as a function of dispersal capacity, level of fire adaptation, endemism, and commonness. Although there were statistical differences between the forecast and hindcast directions with respect to specific group comparisons, the qualitative relationships observed between transferability and species traits were similar whether using AUC values or TI values (Fig. 7). Our results support our expectation that dispersal strategies with the longest distances (wind dispersed, animal dispersed) have the highest transferability, presumably due to an improved capacity to track shifting climate. The capacity of species to track climate change through dispersal has received much attention, as studies have shown that SDM forecasts under varying dispersal assumptions (e.g., limited vs. unlimited dispersal) have different outcomes (Dirnböck and Dullinger 2004, Engler et al. 2009, Morin and Thuiller 2009). This study provides evidence that dispersal capacity in plants influences the temporal transferability of SDMs through time.

Adaptation to fire also influenced SDM transferability. As hypothesized, species with high levels of fire adaptation, those most dependent on fire for reproduction, showed the lowest level of transferability. In particular, fire-obligate seeders had lower transferability than species that exhibited little to no fire adaptation. The distribution of fire will likely be the predominant factor that influences the distribution of fire-adapted species (Dobrowski et al. 2008, Syphard and Franklin 2010), and over 75 years, many of the regions sampled in our data sets have burned. For instance, we determined that roughly $42 \%$ of the historical plot locations (5810 plots) burned at least once during the study period; and many burned several times, based on an historical fire atlas for the state (available online). ${ }^{6}$ Given that SDMs do not account for dynamic disturbance processes such as fire, the lack of this process will differentially affect fire-adapted species (particularly fire-obligate seeders) more than other species. Disturbance in general is a nonequilibrium condition and is poorly handled using static SDM approaches (Guisan et al. 1999, Guisan and Thuiller 2005, Randin et al. 2009b). Consequently, in fire-prone regions, we should view SDM approaches for

\footnotetext{
${ }^{6}\langle$ http://frap.cdf.ca.gov/ $\rangle$
} 
projecting climate change impacts with caution, particularly given contemporary and projected future trends toward larger, more frequent, and severe fires (Westerling et al. 2006, Miller et al. 2008).

As expected, species with intermediate levels of prevalence exhibited the highest transferability (Fig. 7). Common species in our study were widespread generalist tree species (e.g., Pseudosuga menziesii, Pinus ponderosa). Rare species tended to be habitat specialists. Prevalence has been shown to affect model performance, with models of common species yielding more false positive predictions, and models of rare species yielding more false negative predictions (Fielding and Bell 1997). Species rarity can reduce the amount and quality of data for model building if the detection of species is low (Kadmon et al. 2003, McPherson and Jetz 2007). Further, SDMs for common species with broad ecological tolerances have been shown to exhibit lower skill (Kadmon et al. 2003, McPherson and Jetz 2007, Syphard and Franklin 2010) because it may be difficult to distinguish between suitable and unsuitable environments for habitat generalists. This suggests that species with intermediate levels of prevalence may be optimal in terms of IE and for optimizing transferability.

Contrary to expectations, endemic species exhibited lower transferability than non-endemics (Fig. 7). Our presumption that models for endemic species would exhibit greater transferability than non-endemics was not consistent with our results. Instead, this finding is best explained by the fact that endemic species tend to have covarying suites of traits. Mediterranean-type climatic regions (including most of California) present a common set of strong selective forces (e.g., fire, drought, high dry-season temperatures, unpredictable rainfall, general mineral deficiencies) that have resulted in convergence toward common life-forms, life-history traits, and fire response strategies in many plant lineages (Mooney and Dunn 1970, Ackerly 2003, Syphard and Franklin 2010). Results from a contingency table analysis suggest that endemics in our analysis have a higher incidence of ballistic dispersal strategies and obligate seeding after fire than would be expected, given their proportion in the data set (results not shown). Similarly, species with high fire adaptation have higher incidence of ballistic dispersal than would be expected otherwise (results not shown). Similar results were presented by Syphard and Franklin (2010). Species with ballistic dispersal and high fire adaptation had the lowest values of transferability examined here; thus, the significance of the test on endemism may be a consequence of the fact that SDM transferability was low for this suite of interdependent traits. When endemism was included in a multiple regression model with both dispersal and fire adaptation as predictors of TI, its effect remained significant (Table 3). However, we caution against the overinterpretation of this result due to potential collinearity between the terms. Environmental tolerances, physiological adaptations, and life history tend to covary with disturbance response functional types (Keeley 1998, Syphard and Franklin 2010). The classification of species with similar disturbance response strategies has proven to be a useful framework for analysis in plant community ecology and evolutionary ecology (Ackerly 2003, Pausas and Lavorel 2003, McGill et al. 2006) as well as niche modeling (Syphard and Franklin 2010). Disturbance response functional types may also prove to be a useful classification framework for assessing SDM transferability.

The traits that make a species amenable to making predictions in a single time period may not be useful for achieving transferability between time periods. As a particularly relevant example of this, we summarize findings from Syphard and Franklin (2010), who modeled 45 species in southern California using the same historical data source that we used in this analysis. These authors demonstrate that species with the strongest internal prediction accuracies are species that exhibit the greatest site fidelity: obligate seeders with persistent seed banks and short dispersal distances. Indeed, species with these traits may be most amenable to modeling in a single time period because, as the authors argue, species with these traits are most easily detected and have the narrowest ecological tolerances. However, our results suggest that these same traits make these species the least likely to be transferable in time because they strain the assumption of species-environment equilibrium and expose a weakness of the SDM approach: the inability to account for disturbance processes. Given that our data included the same plot data set, dispersal classification, and a similar fire classification system (in fact we corroborated our classification against that published by these authors for the subset of species used in their analysis), we believe that these divergent results are indicative of what Peterson et al. (2007) describe as the contrasting challenges faced by SDMs: making accurate predictions in a well-sampled region in a single time period, and a very different challenge: making accurate projections into novel regions and time periods. The contrasting results of these two studies is notable as it suggests that results from studies that relate species traits to measures of model skill in a single time period may not be applicable to assessing transferability in time.

Variability in model performance (EE) was driven predominantly by differences among species as opposed to differences in model approach, time period (forecast or hindcast), or sample stratification. Differences in these latter factors were in some cases statistically significant; for example, there were differences in performance among model algorithms, but the magnitude of these differences was small compared to the variability in EE observed across species. This highlights the importance of testing transferability on a large number of species in order to understand constraints on transferability (Randin et al. 2006). It also brings into 
question the pervasive attention that model comparisons have received in the SDM literature (e.g., Elith et al. 2006). Certainly, there were differences in EE introduced by model algorithm, but our findings suggest that these differences may not be strategically important in understanding transferability (Guisan et al. 2007, Syphard and Franklin 2010).

Despite our attempts at identifying and ameliorating the effects of sample bias between time periods, its influence may still persist in our analysis. Our approach assessed bias as a function of sampled climate space; i.e., the analog sample ensured that models were calibrated and evaluated on samples representing the same climatic domain. However, we did not guard against geographic bias. Challenges to transferability may arise when projecting models into novel geographic regions independent of climate, because the influence of geographic bias may relate to a host of factors including localized adaptations of species (ecotypes), edaphic factors, source populations, and geomorphic features that are region specific (Randin et al. 2006). The influence of this effect is not easily characterized, but we rule out the possibility that systematic geographic biases can account for our results. If such bias could explain the linkage between transferability and species ecological traits, then these biases would have to have been consistent between our historical and modern data, as both were used in calculating the TI metric. This is unlikely, because these data sets were collected independently.

\section{Conclusions}

Forecasts of species responses to future climate change scenarios based on SDMs are alarming (Thomas et al. 2004, Iverson et al. 2007, Loarie et al. 2008). These projections play a critical role in informing resource management and conservation strategies (e.g., Cutko 2009) aimed at mitigating climate change impacts on biota (Wilson et al. 2005). The work presented here demonstrates that the predictive performance of future projections from SDMs (EE) is likely to be lower and more variable than what IE estimates suggest. Further, SDM temporal transferability is sensitive to species traits and violations of the equilibrium assumption of the approach. In light of these findings, we outline three areas that we feel are important to advancing the field:

First, greater attention should be paid to the assessment of SDM transferability in climate change impact studies. To these ends, emphasis should be placed on the use of historical data and spatially independent data sets for use in evaluating SDM projections. Examples of methods for applying and evaluating SDMs across multiple timeframes are lacking. Related to this is the need for appropriate methods for identifying sampling bias in multi-temporal data sets and an assessment of its effect on transferability. Sampling bias is an issue that invariably affects SDM projections made within a single time period (Phillips et al. 2009), although it is unclear how large an effect this has, as there has been surprisingly little research examining how to quantify and ameliorate sampling bias. However, the influence of sampling bias is likely to be even more pronounced when examining the transferability of SDMs, as it can lead to erroneous projections through time and space and compromise our ability to estimate the skill of these projections (Peterson et al. 2007, Phillips et al. 2009).

Second, there is a need for further research that relates species functional traits to metrics of transferability. It is clear from multiple studies that differences between species are the largest driver of variability in SDM performance within a single time period. Our findings suggest that species traits and disturbance response strategies influence SDM transferability as well. In addition to interspecific variability in functional traits, there is also evidence suggesting that intraspecific variability in functional traits measured along environmental gradients relates to the accuracy of habitat suitability estimated using SDMs, although the pattern is not generalizable in all cases (Thuiller et al. 2010). To date, much of the research relating functional traits to SDM performance has been exploratory or correlative, whereas there have been fewer attempts to ground this research in a more theoretical framework. Future research should provide a priori hypotheses about the transferability of SDMs based on life-history strategies (e.g., Grime 1977) or plant functional traits (Westoby et al. 2002), and should assess these hypotheses with observed performance. Progress in this area would help to link niche modeling to other ecological disciplines including community, functional, and evolutionary ecology (Ackerly 2003, Pausas and Lavorel 2003).

Third, a consensus is emerging that efforts should be made to develop ways to quantify the level of uncertainty in SDM projections (Wiens et al. 2009). This is a critical first step in providing managers with information that can be tactically used for interpreting SDM-derived climate change impact projections. Uncertainty in SDM projections can arise from many sources including (but not limited to) errors in climate data, scale uncertainties, uncertainty in occurrence records, and errors in model specification (Barry and Elith 2006). Studies employing SDM ensembles have demonstrated that model approach and GCM scenario greatly influence projection uncertainty (e.g., DinizFilho et al. 2009, Buisson et al. 2010). There are far fewer examples of studies that characterize multiple sources of uncertainty in a single SDM approach (see Latimer et al. [2006] for an example involving a Bayesian hierarchical model that incorporates spatial random effects). As a consequence, we have a limited understanding of the intrinsic utility of this tool in conservation and management applications. We highlight this point by noting that multi-temporal analyses are one of the only means to directly quantify the actual skill with which SDMs can identify suitable habitat through time. The use of temporally independent validation data with 
SDM uncertainty projections should greatly improve our understanding of the relative importance of the sources of uncertainty in SDM development and the nature of the prediction errors they create. From a conservation and management perspective, the nature of prediction errors is particularly important, as there are disparate costs associated with consistently making errors of omission vs. commission (Wiens et al. 2009).

Despite the myriad of assumptions, limitations, and challenges with using SDMs for forecasting climate change responses, they remain the most plausible means by which we can translate climate change scenarios to ecological outcomes. As such, it is important that we understand the transferability of these models and the factors that influence their generality. Advances in these areas are likely to help focus our research efforts, improve the skill of SDMs, and result in a greater understanding of their ability to predict the effects of climate change on biota.

\section{ACKNOWLEDGMENTS}

The authors acknowledge funding provided by the National Science Foundation (grant award \#0819430) and the California Energy Commission PIER Program (CEC PIR-08-006). We thank the PRISM group for providing climate data, and many agencies and institutions who have collected and stewarded the historical and modern inventory data used in the analysis.

\section{Literature Cited}

Ackerly, D. D. 2003. Community assembly, niche conservatism, and adaptive evolution in changing environments. International Journal of Plant Science 164:S165-S184.

Allen, R. G., L. S. Pereira, D. Raes, and M. Smith. 1998. Crop evapotranspiration: guidelines for computing crop water requirements. FAO Irrigation and Drainage Paper 56. Food and Agriculture Organization of the United Nations, Rome, Italy.

Allouche, O., A. Tsoar, and R. Kadmon. 2006. Assessing the accuracy of species distribution models: prevalence, kappa, and the true skill statistic. Journal of Applied Ecology 43:1223-1232.

Araújo, M. B., and M. New. 2007. Ensemble forecasting of species distributions. Trends in Ecology and Evolution 22:42-47.

Araújo, M. B., R. G. Pearson, W. Thuiller, and M. Erhard. 2005. Validation of species-climate impact models under climate change. Global Change Biology 11:1504-1513.

Barry, S., and J. Elith. 2006. Error and uncertainty in habitat models. Journal of Applied Ecology 43:413-423.

Bonner, F. T., and R. P. Karrfalt, editors. 2008. The woody plant seed manual. Agriculture Handbook 727. USDA Forest Service, Washington, D.C., USA.

Boyce, M. S., P. R. Vernier, and S. E. Nielsen. 2002. Evaluating resource selection functions. Ecological Modeling 157:281300.

Breiman, L. 2001. Random forests. Machine Learning 45:5-32.

Buisson, L., W. Thuiller, N. Casajus, S. Lek, and G. Grenouillet. 2010. Uncertainty in ensemble forecasting of species distributions. Global Change Biology 16:1145-1157.

Burns, R. M., and B. H. Honkala. 1990. Silvics of North America. Volumes 1 and 2. Agriculture Handbook 654. USDA Forest Service, Washington, D.C., USA.

Busby, J. R. 1991. BIOCLIM: a bioclimate analysis and prediction system. Plant Protection Quarterly 6:8-9.

Cantor, S. B., C. C. Sun, G. Tortolero-Luna, R. RichardsKortum, and M. Follen. 1999. A comparison of C/B ratios from studies using receiver operating characteristic curve analysis. Journal of Clinical Epidemiology 52:885-892.

Cayan, D. R., S. A. Kammerdiener, M. D. Dettinger, J. M. Caprio, and D. H. Peterson. 2001. Changes in the onset of spring in the western United States. Bulletin of the American Meteorological Society 82:399-415.

Cutko, A. 2009. Biodiversity inventory of natural lands: a howto manual for foresters and biologists. NatureServe, Arlington, Virginia, USA.

Daly, C., M. Halbleib, J. I. Smith, W. P. Gibson, M. K. Dogget, G. H. Taylor, J. Curtis, and P. P. Pasteris. 2008. Physiographically sensitive mapping of climatological temperature and precipitation across the conterminous United States. International Journal of Climatology 28:2031-2064.

Davis, A. J., L. S. Jenkinson, J. H. Lawton, B. Shorrocks, and S. Wood. 1998. Making mistakes when predicting shifts in species range in response to global warming. Nature 391:783786.

De'ath, G. 2008. Boosted trees for ecological modeling and prediction. Ecology 88:243-251.

Dettinger, M. D., and D. Cayan. 1995. Large-scale atmospheric forcing of recent trends toward early snowmelt runoff in California. Journal of Climate 8:606-623.

Diniz-Filho, J. A. F., L. M. Bini, T. F. Rangel, R. D. Loyola, C. Hof, D. Nogués-Bravo, and M. Araújo. 2009. Partitioning and mapping uncertainties in ensemble forecasts of species turnover under climate change. Ecography 32:897-906.

Dirnböck, T., and S. Dullinger. 2004. Habitat distribution models, spatial autocorrelation, functional traits and dispersal capacity of alpine plant species. Journal of Vegetation Science 15:77-84.

Dobrowski, S. Z., H. D. Safford, Y. B. Cheng, and S. L. Ustin. 2008. Mapping mountain vegetation using species distribution modeling, image-based texture analysis, and objectbased classification. Applied Vegetation Science 11:499-508.

Duncan, R. P., P. Cassey, and T. M. Blackburn. 2009. Do climate envelope models transfer? A manipulative test using dung beetle introductions. Proceedings of the Royal Society 267:1449-1457.

Elith, J., et al. 2006. Novel methods improve prediction of species distributions from occurrence data. Ecography 29:129-151.

Elith, J., and J. R. Leathwick. 2009. Species distribution models: ecological explanation and prediction across space and time. Annual Review of Ecology, Evolution, and Systematics 40:677-697.

Elith, J., J. R. Leathwick, and T. Hastie. 2008. A working guide to boosted regression trees. Journal of Animal Ecology 77:802-813.

Engler, R., C. F. Randin, P. Vittoz, T. Czaka, M. Beniston, N. E. Zimmerman, and A. Guisan. 2009. Predicting future distributions of mountain plants under climate change: does dispersal capacity matter? Ecography 32:34-45.

ESRI. 2008. Solar radiation tools. ArcGIS 9.3. Environmental Systems Research Institute, Redlands, California, USA.

Fielding, A. H., and J. F. Bell. 1997. A review of methods for the assessment of prediction errors in conservation presence/ absence models. Environmental Conservation 24:38-49.

Fielding, A. H., and P. F. Haworth. 1995. Testing the generality of bird-habitat models. Conservation Biology 9:1466-1481.

Fitzpatrick, M. C., and W. W. Hargrove. 2009. The projection of species distribution models and the problem of non-analog climate. Biodiversity Conservation 18:2255-2261.

Fitzpatrick, M. C., J. F. Weltzin, N. J. Sanders, and R. J. Dunn. 2007. The biogeography of prediction error: why does the introduced range of the fire ant over-predict its native range? Global Ecology and Biogeography 16:24-33.

Franklin, J., C. L. Coulter, and S. J. Rey. 2004. Change over 70 years in a southern California chaparral community related to fire history. Journal of Vegetation Science 15:701-710. 
Givnish, T. J. 2002. Adaptive significance of evergreen vs. deciduous leaves: solving the triple paradox. Silva Fennica 36:703-743.

Grime, J. 1977. Evidence for the existence of three primary strategies in plants and its relevance to ecological and evolutionary theory. American Naturalist 111:1169-1194.

Guisan, A., and W. Thuiller. 2005. Predicting species distribution: offering more than simple habitat models. Ecology Letters 8:993-1009.

Guisan, A., S. Weiss, and A. Weiss. 1999. GLM versus CCA spatial modeling of plant species distribution. Plant Ecology 143:107-122.

Guisan, A., and N. E. Zimmerman. 2000. Predictive habitat distribution models in ecology. Ecological Modeling 135:147-186.

Guisan, A., N. E. Zimmerman, J. Elith, C. H. Graham, S. J. Phillips, and A. T. Peterson. 2007. What matters for predicting the occurrences of trees: techniques, data, or species characteristics? Ecological Monographs 77:615-630.

Hamlet, A. F., P. W. Mote, M. P. Clark, and D. P. Lettenmaier. 2005. Effects of temperature and precipitation variability on snowpack trends in the western United States. Journal of Climate 18:4545-4561.

Hastie, T. J., and R. Tibshirani. 1990. Generalised additive models. Chapman and Hall, London, UK.

Hickman, J. C., editor. 1993. The Jepson manual: higher plants of California. University of California Press, Berkeley, California, USA.

Iverson, L. R., A. M. Prasad, S. N. Matthews, and M. Peters. 2007. Estimating potential habitat for 134 eastern US tree species under six climate scenarios. Forest Ecology and Management 254:390-406.

Jump, A. S., and J. Penuelas. 2005. Running to stand still: adaptation and the response of plants to rapid climate change. Ecology Letters 8:1010-1020.

Kadmon, R., O. Farber, and A. Danin. 2003. A systematic analysis of factors affecting the performance of climatic envelope models. Ecological Applications 13:853-867.

Keane, R. E., and L. Holsinger. 2006. Simulating biophysical environment for gradient modeling and ecosystem mapping using the WXFIRE program: model documentation and application. Research Paper RMRS-GTR-168CD. USDA Forest Service Rocky Mountain Research Station, Fort Collins, Colorado, USA.

Keeley, J. E. 1998. Coupling demography, physiology and evolution in chaparral shrubs. Pages 237-264 in P. W. Rundel, G. Montenegro, and F. M. Jaksic, editors. Landscape degradation and biodiversity in Mediterranean type ecosystems. Springer-Verlag, Berlin, Germany.

Kelly, M. B., B. Allen-Diaz, and N. Kobzina. 2005. Digitization of a historic dataset: the Wieslander California Vegetation Type Mapping Project. Madroño 52:191-202.

Kharouba, H. M., A. C. Algar, and J. T. Kerr. 2009. Historically calibrated predictions of butterfly species range shift using global change as a pseudo-experiment. Ecology 90:2213-2222.

Kikuzawa, K. 1991. A cost-benefit analysis of leaf habit and leaf longevity of trees and their geographic pattern. American Naturalist 138:1250-1263.

LaDochy, S., R. Medina, and W. Patzert. 2007. Recent California climate variability: spatial and temporal patterns in temperature trends. Climate Research 33:159-169.

Latimer, A. M., S. Wu, A. E. Gelfand, and J. A. Silander. 2006. Building statistical models to analyze species distributions. Ecological Applications 16:33-50.

Liu, C., P. M. Berry, T. P. Dawson, and R. G. Pearson. 2005. Selecting thresholds of occurrence in the prediction of species distributions. Ecography 28:385-393.

Loarie, S. R., B. E. Carter, K. Hayhoe, S. McMahon, R. Moe, C. A. Knight, and D. D. Ackerly. 2008. Climate change and the future of California's endemic flora. PLoS ONE 3:e2502.
Loehle, C., and D. Leblanc. 1996. Model-based assessments of climate change effects on forests: a critical review. Ecological Modelling 90:1-31.

Luoto, M., and R. K. Heikkinen. 2008. Disregarding topographical heterogeneity biases species turnover assessments based on bioclimatic models. Global Change Biology 14:483-494.

McCullagh, P., and J. A. Nelder. 1989. Generalized linear models. Second edition. Chapman and Hall, London, UK.

McGill, B. J., B. J. Enquist, E. Weiher, and M. Westoby. 2006. Rebuilding community ecology from functional traits. Trends in Ecology and Evolution 21:178-185.

McPherson, J. M., and W. Jetz. 2007. Effects of species ecology on the accuracy of distribution models. Ecography 30:135151.

Medley, K. A. 2010. Niche shifts during the global invasion of the Asian tiger mosquito, Aedes albopictus Skuse (Culicidae), revealed by reciprocal distribution models. Global Ecology and Biogeography 19:122-133.

Miller, J. D., H. D. Safford, M. Crimmins, and A. E. Thode. 2008. Quantitative evidence for increasing forest fire severity in the Sierra Nevada and southern Cascade mountains, California and Nevada USA. Ecosystems 12:16-32.

Mooney, H. A., and E. L. Dunn. 1970. Convergent evolution of mediterranean-climate evergreen sclerophyll shrubs. Evolution 24:292-303.

Morin, X., and W. Thuiller. 2009. Comparing niche and process based models to reduce prediction uncertainty in species range shifts under climate change. Ecology 90:13011313.

Murphy, J. M., D. M. H. Sexton, D. N. Barnett, G. S. Jones, M. J. Webb, M. Collins, and D. A. Stainforth. 2004. Quantification of modelling uncertainties in a large ensemble of climate change simulations. Nature 430:768-772.

Myers, N., R. A. Mittermeier, C. G. Mittermeier, G. A. B. da Fonseca, and J. Kent. 2000. Biodiversity hotspots for conservation priorities. Nature 403:853-858.

National Renewable Energy Laboratory. 2009. High-resolution wind data: validated maps produced by AWS TrueWind. National Renewable Energy Laboratory, Golden, Colorado, USA. 〈http://www.windpoweringamerica.gov/maps_template. asp?stateab=ca $\rangle$

Nogués-Bravo, D. 2009. Predicting the past distribution of species climatic niches. Global Ecology and Biogeography 18:521-531.

Palmer, T. N. 2000. Predicting uncertainty in forecasts of weather and climate. Reports on Progress in Physics 63:71116.

Parmesan, C. 2006. Ecological and evolutionary responses to recent climate change. Annual Review of Ecology, Evolution, and Systematics 37:637-669.

Pausas, J. G., and S. Lavorel. 2003. A hierarchical deductive approach for functional types in disturbed ecosystems. Journal of Vegetation Science 14:409-416.

Pearman, P. B., C. F. Randin, P. Van der Knaap, G. Le Lay, R. Engler, P. Vittoz, O. Broennimann, and A. Guisan. 2008. Prediction of plant species distributions across six millennia. Ecology Letters 11:1-12.

Pearson, R. G., and T. P. Dawson. 2003. Predicting the impacts of climate change on the distribution of species: are bioclimate envelope models useful? Global Ecology and Biogeography 12:361-371.

Peterson, A. T., M. A. Ortega-Huerta, J. Bartley, V. SanchezCordero, J. Soberton, R. H. Buddemeier, and D. R. B. Stockwell. 2002. Future projections for Mexican faunas under global climatic change scenarios. Nature 416:626629.

Peterson, A. T., M. Papes, and M. Eaton. 2007. Transferability and model evaluation in ecological niche modeling: a comparison of GARP and Maxent. Ecography 30:550-560. 
Phillips, S. J. 2008. Transferability, sample selection bias, and background data in presence-only modelling: a response to Peterson et al. (2007). Ecography 31:272-278.

Phillips, S. J., M. Dudik, J. Elith, C. Graham, A. Lehman, J. Leathwick, and S. Ferrier. 2009. Sample selection bias and presence-only distribution models: implications for background and pseudo-absence data. Ecological Applications 19:181-197.

R Development Core Team. 2009. R version 2.9. R Foundation for Statistical Computing, Vienna, Austria.

Randin, C. F., T. Dirnbock, S. Dullinger, N. E. Zimmerman, M. Zappa, and A. Guisan. 2006. Are niche-based species distribution models transferable in space? Journal of Biogeography 33:1689-1703.

Randin, C. F., R. Engler, S. Normand, M. Zappa, N. E. Zimmerman, P. B. Pearman, P. Vittoz, W. Thuiller, and A. Guisan. 2009a. Climate change and plant distribution: local models predict high-elevation persistence. Global Change Biology 15:1557-1569.

Randin, C. F. G. Vuissoz, G. Liston, P. Vittoz, and A. Guisan. editors. 2009b. Introducing snow and geomorphic disturbance variables into predictive models of alpine plant distribution in the Western Alps. Arctic, Antarctic, and Alpine Research 41:347-361.

Schopmeyer, C. S. 1974. Seeds of woody plants in the United States. Agriculture Handbook 450. USDA Forest Service, Washington, D.C., USA.

Schurr, F. M., G. F. Midgley, A. G. Rebelo, G. Reeves, P. Poschlod, and S. I. Higgins. 2007. Colonization and persistence ability explain the extent to which plant species fill their potential range. Global Ecology and Biogeography 16:449-459.

Segurado, P., and M. B. Araújo. 2004. An evaluation of methods for modeling species distributions. Journal of Biogeography 31:1555-1568.

Seo, C., J. H. Thorne, L. Hannah, and W. Thuiller. 2009. Scale effects in species distribution models: implications for conservation planning under climate change. Biology Letters 5:39-43.

Sugihara, N. G., J. W. van Wagtendonk, K. E. Shaffer, J. FitesKaufman, and A. E. Thode, editors. 2006. Fire in California's ecosystems. University of California Press, Berkeley, California, USA.

Svenning, J. C., and F. Skov. 2004. Limited filling of the potential range in European tree species. Ecology Letters 7:565-573.

Sykes, M. T., I. C. Prentice, and W. Cramer. 1996. A bioclimatic model for the potential distributions of north European tree species under present and future climates. Journal of Biogeography 23:203-233.

Syphard, A. D., and J. Franklin. 2010. Species traits affect the performance of species distribution models for plants in southern California. Journal of Vegetation Science 21:177189.

Thomas, C. D., et al. 2004. Extinction risk from climate change. Nature 427:145-147.
Thorne, J. H., B. J. Morgan, and J. A. Kennedy. 2008. Vegetation change over sixty years in the central Sierra Nevada, California, USA. Madroño 55:223-237.

Thorne, J. H., J. H. Viers, J. Price, and D. M. Storms. 2009. Spatial patterns of endemic plants in California. Natural Areas Journal 29:344-366.

Thuiller, W., C. H. Albert, A. Dubuis, C. Randin, and A. Guisan. 2010. Variation in habitat suitability does not always relate to variation in species' plant functional traits. Biology Letters 6:120-123.

Thuiller, W., L. Brotons, M. B. Araújo, and S. Lavorel. 2004. Effects of restricting environmental range of data to project current and future species distributions. Ecography 27:165172.

Thuiller, W., B. Lafourcade, R. Engler, and M. B. Araújo. 2009. BIOMOD: a platform for ensemble forecasting of species distributions. Ecography 32:369-373.

Thuiller, W., S. Lavorel, and M. B. Araújo. 2005. Niche properties and geographical extent as predictors of species sensitivity to climate change. Global Ecology and Biogeography 14:347-357.

Urban, M. C., B. L. Phillips, D. K. Skelly, and R. Shine. 2007. The cane toad's (Chaunus [Bufo] marinus) increasing ability to invade Australia is revealed by a dynamically updated range model. Proceedings of the Royal Society B 274:1413-1419.

VanReusel, W., D. Maes, and H. Van Dyck. 2007. Transferability of species distribution models: a functional habitat approach for two regionally threatened butterflies. Conservation Biology 21:201-212.

Westerling, A. L., H. G. Hidalgo, D. R. Cayan, and T. W. Swetnam. 2006. Warming and earlier spring increase western U.S. forest wildfire activity. Science 313:940-943.

Westoby, M., D. Falster, A. Moles, P. Vesk, and I. Wright. 2002. Plant ecological strategies: some leading dimensions of variation between species. Annual Review of Ecology and Systematics 33:125-159.

Wiens, J. A., and D. Bachelet. 2010. Matching the multiple scales of conservation with the multiple scales of climate change. Conservation Biology 24:51-62.

Wiens, J. A., D. Stralberg, D. Jonsomjit, C. A. Howell, and M. A. Snyder. 2009. Niches, models, and climate change: assessing the assumptions and uncertainties. Proceedings of the National Academy of Sciences USA 106:19729-19736.

Wieslander, A. E. 1935a. A vegetation type map for California. Madroño 3:140-144.

Wieslander, A. E. 1935b. First steps of the forest survey in California. Journal of Forestry 33:877-884.

Williams, J. W., and S. T. Jackson. 2007. Novel climates, noanalog communities, and ecological surprises. Frontiers in Ecology and the Environment 5:475-482.

Williams, J. W., S. T. Jackson, and J. E. Kutzbach. 2007. Projected distributions of novel and disappearing climates by 2100 AD. Proceedings of National Academy of Sciences USA 104:5738-5742.

Wilson, K. A., M. I. Westphal, H. P. Possingham, and J. Elith. 2005. Sensitivity of conservation planning to different approaches using predicted species distribution data. Biological Conservation 122:99-112.

\section{APPENDIX}

Summary of species ecological traits (Ecological Archives M081-008-A1). 